\title{
Modeling the stability of the financial system of the country
}

\author{
Valdemar Vitlinskyi ${ }^{1}$, and Liubov Makhanets ${ }^{2,}$ \\ ${ }^{1}$ Kyiv National Economics University named after Vadym Hetman, Institute Information Technologies in Economics, Kyiv, Ukraine \\ ${ }^{2}$ Yuriy Fedkovych Chernivtsi National University, Faculty of Economics, Chernivtsi, Ukraine
}

\begin{abstract}
The security of the public finance sector of Ukraine requires monitoring of indicators of the stability of the financial system of the country, as well as modeling the impact of these indicators on the country's financial security. It is shown that the stability of the financial system of the economy can be checked with the help of the provisions of econophysics. The concept of equilibrium is using to determine stability. The influence of factors on the level of financial security, which is one of the aspects of assessing the stability of the financial system of Ukraine is able to evaluate by simulation. The model of the financial system stability of the country is constructed in the paper. This research can serve as the basis for the adoption by the relevant state institutions of sound decisions on ensuring the stability of the financial system of Ukraine.
\end{abstract}

\section{Introduction}

At the present stage the main threat to the security of the public finance sector of Ukraine is the deepening of the economic crisis. The deterioration in the financial position of enterprises and banks increases the risks of a lack of government revenue and leads to an increase in the state budget deficit and in public debt. All this requires monitoring of indicators of the stability of the financial system of the country, as well as modeling the impact of these indicators on the country's financial security.

The list of indicators to be monitored should include those indicators that have the most significant impact on the sovereign credit rating of the country [1], taking into account the constraints defined, in particular, by singlefactor models [2], as well as the indicators recommended by the Ministry of Economic Development and Trade of Ukraine for the assessment of the budget security [3].

The negative impact of military actions on the country's economy in 2014 has weakened the sustainability of public finances in Ukraine. The probability of default has increased, which is reflected in the corresponding reaction of the financial markets and the growth of the spread between the level of yield of debt obligations of Ukraine and the US from 5.9 in. in 2010 to 9.3 in. in 2014 [4]. Exceeding all parameters of the debt dependence of safe levels starting from 2014 in conjunction with the increase of currency risks, deteriorating financial situation of the real and banking sectors in the context of military operations in the East of the country creates a critically high threat to the stability of the financial system of Ukraine.

\section{Data and methods}

Since, according to the above-mentioned method the greatest impact on the stability of the country's financial system have the GDP and gross external debt, let us analyze them for the presence of a trend, that is, a steady trend.

More reliable estimates of the sustainable development of the financial system are the analysis of fractal time series of the dominant parameters of the functioning of the system and the creation of a model for its fractal development [5].

The method of normalized scope and the estimation of the Hurst index is an effective method of studying fractal characteristics of time series in forecasting the dynamics of economic indicators of the enterprise. The main difference between the normalized scale method or the $R / S$ prediction method from other statistical methods is that this method includes in its analysis the direction of time, while other methods are invariant with respect to time.

The application of the method involves the following steps, which are described in [6].

By the value of the Hurst index, it can be concluded:

1) If $H=0.5$, the economic process is a random walk, and the scale of accumulated deviations should increase proportionally to the square root of the time.

2) $0<H \leq 0.5$. This range corresponds to the ergodic anti-persistent series. This type of process is often referred to as "return to the average".

The anti-persistent time series is more variable than a series of random ones, since it consists of frequent "rebound" reverses. If the process demonstrates an increase in the previous period, then the next period is most likely to begin to decline. Conversely, if there was a downturn, then the upsurge is likely to happen. The stability of this behavior depends on how close $H$ is to zero. The closer its value to zero, the greater the value of the coefficient of negative auto-correlation of the time series levels is.

3 ) If $0.5<H \leq 1.0$ then it is persistent, or trend-stable rows. If the series increases (decreases) in the previous period, then it is likely to keep this trend for some time in

*Corresponding author:1.makhanets@chnu.edu.ua 
the future (trends are obvious). Trend-stability of behavior, or strength of persistence, increases with the degree of approximation of $H$ to unit, or $100 \%$ of autocorrelation. The closer $H$ is to 0.5 , the more a series is exposed to noise and the less pronounced its trend.

Persistent series is a generalized Brownian motion, or accidental wandering with drift. The shear force depends on how much $H$ exceeds 0.5 . Such ranks are unstable, they are characteristic of the capital markets. The persistent time series has a long-lasting memory, so there are longterm correlations between current events and future events.

The fact that $H$ differs from 0.5 means that observations are not independent. Each observation carries the memory of all past events. This is not a shortlived memory, often referred to as "Markov". This is another memory - a long-term, in theory it is stored for a sufficiently long period. That is, recent events have a more powerful effect than events are remote, but the residual effects of the latter are always tangible.

\section{Results}

Data for carrying out $R / S$ are presented in Table 1 .

Table 1. Estimated data for the analysis of the sustainability of GDP and gross external debt $\left(G^{e x}\right)$.

\begin{tabular}{|l|l|l|l|l|}
\hline$\#$ & $\ln (\mathbf{R} / \mathbf{S}) \_$GDP & $\ln (\mathbf{n}) \_$GDP & $\ln (\mathbf{R} / \mathbf{S}) \_$GD & $\mathbf{l n}(\mathbf{n}) \_$GD $\mathbf{e x}$ \\
\hline $\mathbf{1}$ & 1.10068659 & 3.17805383 & 1.04352951 & 3.17805383 \\
\hline $\mathbf{2}$ & 1.08150729 & 3.13549422 & 1.02549389 & 3.13549422 \\
\hline $\mathbf{3}$ & 1.06451688 & 3.09104245 & 1.01737242 & 3.09104245 \\
\hline $\mathbf{4}$ & 1.05453218 & 3.04452244 & 1.00313217 & 3.04452244 \\
\hline $\mathbf{5}$ & 1.04858468 & 2.99573227 & 1.00131357 & 2.99573227 \\
\hline $\mathbf{6}$ & 1.04763452 & 2.94443898 & 0.998764675 & 2.94443898 \\
\hline $\mathbf{7}$ & 1.04369136 & 2.89037176 & 0.996824462 & 2.89037176 \\
\hline $\mathbf{8}$ & 1.05215859 & 2.83321334 & 1.00690501 & 2.83321334 \\
\hline $\mathbf{9}$ & 1.08426639 & 2.77258872 & 1.02762892 & 2.77258872 \\
\hline $\mathbf{1 0}$ & 1.08895394 & 2.7080502 & 1.00029172 & 2.7080502 \\
\hline $\mathbf{1 1}$ & 1.11848259 & 2.63905733 & 1.02620852 & 2.63905733 \\
\hline $\mathbf{1 2}$ & 1.14601263 & 2.56494936 & 1.06203919 & 2.56494936 \\
\hline $\mathbf{1 3}$ & 1.14076836 & 2.48490665 & 1.09404997 & 2.48490665 \\
\hline $\mathbf{1 4}$ & 1.06445657 & 2.39789527 & 1.18892034 & 2.39789527 \\
\hline $\mathbf{1 5}$ & 1.1027381 & 2.30258509 & 1.23596231 & 2.30258509 \\
\hline $\mathbf{1 6}$ & 1.12551333 & 2.19722458 & 1.22235815 & 2.19722458 \\
\hline $\mathbf{1 7}$ & 1.06595083 & 2.07944154 & 1.17397935 & 2.07944154 \\
\hline $\mathbf{1 8}$ & 1.08108497 & 1.94591015 & 1.24219891 & 1.94591015 \\
\hline $\mathbf{1 9}$ & 1.05547763 & 1.79175947 & 1.06003317 & 1.79175947 \\
\hline $\mathbf{2 0}$ & 0.969570178 & 1.60943791 & 1.0434659 & 1.60943791
\end{tabular}

\begin{tabular}{|l|l|l|l|l|}
\hline $\mathbf{2 0}$ & 0.969570178 & 1.60943791 & 1.04344059 & 1.60943791 \\
\hline
\end{tabular}

Source: Calculated by the authors on the basis of statistical data $[7-9]$

In Fig. 1 and 2 are the normalized magnitudes for the analyzed parameters.

The calculated Hurst indicator for GDP is 0.014 , which means that the GDP is anti-persistent and unstable (Fig. 1). A number of gross external debt is also antipersistent and unstable $(H=0.11)$ (Fig. 2).

The above calculations point to the volatility of the dynamic series of key macroeconomic indicators of economic development.

Also, the stability of the financial system of the economy can be checked with the help of the provisions of econophysics. The possibility of using models borrowed from physics in the study of economic problems is considered in many works of scientists, where it is proposed to use not only the concepts borrowed from statistical physics but also classical mechanics in the study of economics.

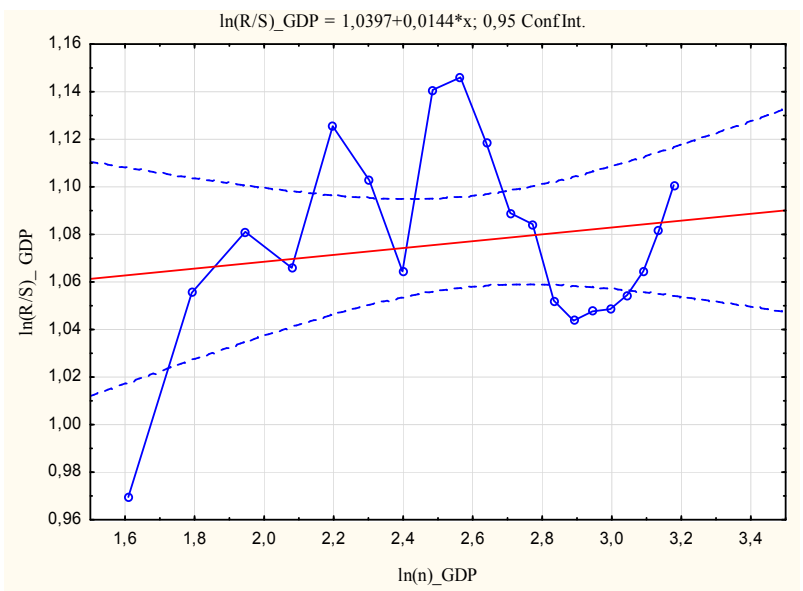

Fig. 1. Value $R / S$ for GDP.

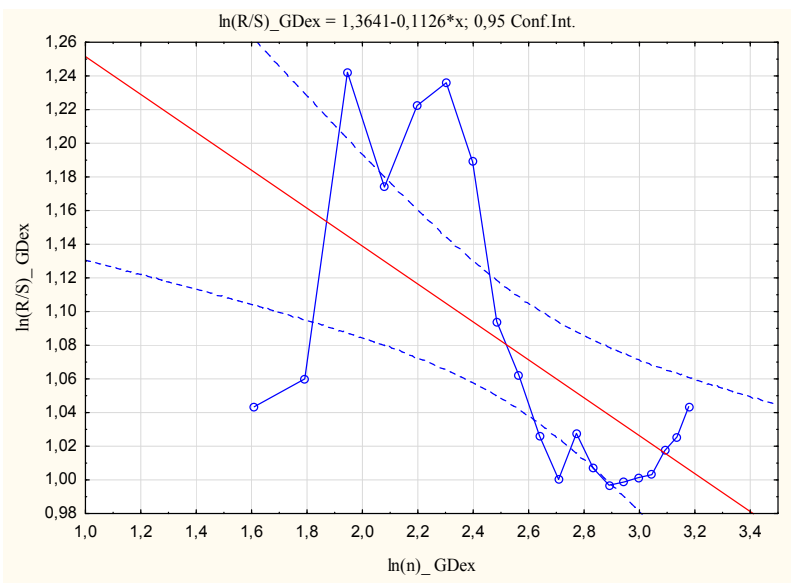

Fig. 2. The ratio $R / S$ for gross external debt.

To determine stability, it is offered using the concept of equilibrium. From the second law of Newton it follows that if the vector sum of all forces applied to the body is zero, then the body retains its speed unchanged. In particular, if the initial velocity is zero, the body remains unchangeble.

Let us assume that the force that wants to shift the economy from a stable state in our coordinate system (financial stability) is the amount of gross external debt, and the force that opposes it is the volume of GDP. Then, in order for the financial system of the country to remain in a stable state, it is necessary that the ratio of gross debt to GDP does not exceed 1. This indicator is called the coefficient of stability of the financial system of the country.

The dynamics of the stability coefficient of the financial system of Ukraine, calculated according to statistical data, is given in Fig. 3.

As it can be seen from this indicator, Ukraine's economy has been in an unstable position since 2014 . 


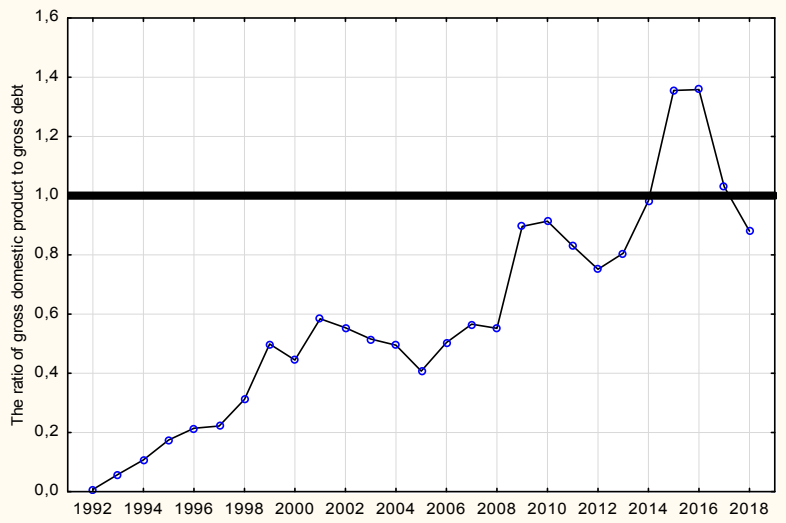

Fig. 3. The coefficient of stability of the financial system of Ukraine in 1992-2018. Source: Calculated by the author on the basis of [9], 2018 - preliminary data.

The considered approach is a bit simplistic and can serve as a quick, rapid analysis of the sustainability of the country's financial system.

Achieving an acceptable level of stability of the financial system requires the subjects of financial relations to continuously improve the measures to identify existing and potential threats and directions for their elimination in all areas of financial activity. That is why it is necessary to be able to evaluate the influence of factors on the level of financial security, which is one of the aspects of assessing the stability of the financial system of Ukraine.

In order to assess the level and dynamics of external debt load and monitor the use of external loans and loans, the National Bank of Ukraine has developed its own indicator system. It consists of 18 indicators and adequately reflects the risks that may be encountered by the banking and financial systems of Ukraine and allows us to analyze the stability of the Ukrainian financial system [11]. Calculated indicators of stability of the financial system of Ukraine are presented in Table 2.

To construct the model, we use the data in Table 2.

Since there is little statistical observation for adequate modeling, we use the bootstrap method for reproduction of the sample, which was proposed in 1977 by B. Efron of Stanford University (USA). As a result of the application of the method, 15 samples were generated. For each sample, a regression model of the dependence of the level of stability of the financial system on GDP, gross external debt, domestic debt, volumes of their servicing, exports of goods and services and consolidated budget revenues was constructed.

Formally, this dependence can be presented as:

$$
\begin{array}{r}
I_{S F}=a+b_{1} G D P+b_{2} D_{e x}+b_{3} D_{i n}+b_{4} S D_{i n}+ \\
+b_{5} S D_{e x}+b_{6} E x+b_{7} P B,
\end{array}
$$

where $I_{S F}$ - the index of financial security level (indicator of stability of the financial system), GDP-nominal gross domestic product; $D_{e x}$ - external public debt; $D_{i n}-$ domestic state debt; $S D_{\text {in }}$ - domestic state debt service; $S D_{e x}$ - servicing of external public debt; $E x$ - total annual export of goods and services; and $P B$ - total annual consolidated budget revenues.
Table 2. Some indicators of stability of the financial system of

\begin{tabular}{|c|c|c|c|c|c|c|c|c|}
\hline 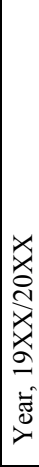 & 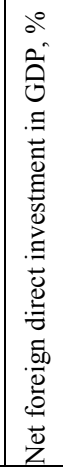 & 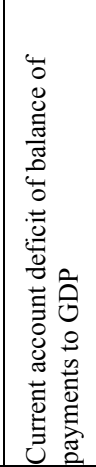 & 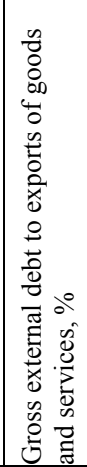 & 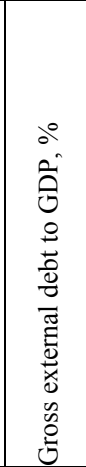 & 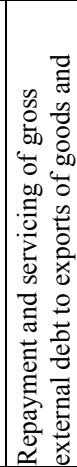 & 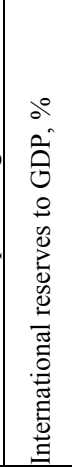 & 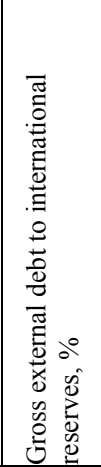 & 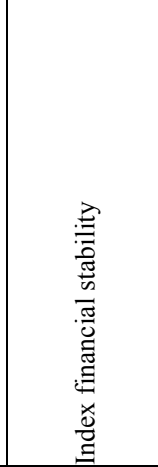 \\
\hline 92 & 0.27 & & 3.11 & 0.74 & & & & 0.602139755 \\
\hline 93 & 0.30 & & 22.69 & 5.87 & & & & \\
\hline 94 & 0.30 & & 30.31 & 10.73 & 1.53 & & & 0.70 \\
\hline 95 & 0.55 & & 37.14 & 17.48 & 6.60 & & & 0.6 \\
\hline 96 & 1.17 & & 46.89 & 21.41 & 6.10 & & & 0.69 \\
\hline 97 & 1.24 & & 54.69 & 22.20 & 5.85 & & & 135 \\
\hline 98 & 1.77 & & 74.49 & 31.20 & 9.08 & & & 0.6 \\
\hline 99 & 1.57 & & 92.85 & 49.87 & 12.46 & & & 196 \\
\hline 00 & 1.90 & -0.004 & 71.25 & 44.49 & 15.16 & & & 543 \\
\hline 01 & 2.08 & -0.004 & 105.33 & 58.42 & 7.24 & 2.95 & 1980.66 & 0.482602966 \\
\hline 02 & 1.63 & -0.008 & 100.54 & 55.39 & 6.37 & 10.54 & 525.40 & 3934 \\
\hline 03 & 2.84 & -0.0058 & 89.32 & 51.58 & 5.90 & 13.85 & 372.47 & $0.7062^{\prime}$ \\
\hline 04 & 2.64 & -0.0107 & 80.84 & 49.48 & 4.86 & 14.97 & 330.47 & 2595 \\
\hline 05 & 9.06 & -0.0029 & 79.14 & 40.74 & 5.08 & 22.51 & 180.99 & 0.893836936 \\
\hline 06 & 5.20 & 0.0015 & 108.01 & 50.36 & 4.91 & 20.75 & 242.71 & 0.712362407 \\
\hline 07 & 7.14 & 0.0037 & 126.17 & 56.58 & 3.73 & 22.76 & 248.62 & 1007893 \\
\hline 08 & 5.94 & 0.0071 & 117.64 & 55.20 & 2.65 & 17.52 & 314.98 & 0.619572418 \\
\hline 09 & 4.07 & 0.0015 & 193.26 & 89.62 & 5.44 & 22.61 & 396.39 & \\
\hline 10 & 4.74 & 0.0022 & 194.22 & 91.39 & 3.22 & 25.42 & 359.49 & 0.569649069 \\
\hline 11 & 4.42 & 0.0063 & 166.66 & 83.03 & 3.14 & 19.49 & 426.06 & 0.521209619 \\
\hline 12 & 4.65 & 0.0082 & 212.15 & 75.13 & 7.60 & 13.96 & 538.04 & 0.464240679 \\
\hline 13 & 2.46 & 0.0090 & 187.51 & 80.55 & 14.98 & 11.14 & 723.25 & 0.384400984 \\
\hline 14 & 0.63 & 0.0034 & 202.25 & 98.28 & 10.54 & 5.64 & 1741.68 & 0.291754202 \\
\hline 15 & 3.37 & 0.0002 & 256.87 & 135.55 & 30.47 & 14.68 & 923.50 & 0.353546944 \\
\hline 16 & 3.39 & 0.0014 & 324.46 & 126.50 & 6.60 & 16.66 & 759.26 & 0.233569629 \\
\hline 17 & 2.52 & 0.0022 & 290.80 & 102.94 & 9.75 & 16.77 & 613.83 & 0.42745074 \\
\hline
\end{tabular}
Ukraine.

Source: Calculated by the authors on the basis of statistical data [7-9]. The index financial stability is developed by the authors [10].

The calculations of the model parameters were carried out in the Statictica system 10 (see Table 3). On the basis of analysis of the estimated parameters for the samples, the estimations of the parameters of the model are found:

$$
\begin{gathered}
a=0.5957, b_{1}=0.000004, b_{2}=-0.000001, \\
b_{3}=-0.00003, b_{4}=-0.00003, b_{5}=-0.0003, \\
b_{6}=0.000006, \text { and } b_{7}=-0.00001 .
\end{gathered}
$$

Consequently, the model given by equation (1), on the basis of the estimated values of the parameters of the model adequately describes the dependence of the level of stability of the financial system on these indicators (see equation (2))

$$
\begin{aligned}
& I_{S F}=0.5975+0.000004 G D P-0.000001 D_{e x}-0.00003 D_{i n}- \\
& -0.00003 S D_{i n}-0.0003 S D_{e x}+0.000006 E x-0.00001 P B,(2)
\end{aligned}
$$

Let's analyze this model. Multiple determination coefficient $\bar{R}^{2}=0,9848$. Consequently, $98.48 \%$ of the variation in the level of stability of the financial system of the country is determined by the variation of the analyzed factors, and $1.52 \%$ - by the influence of unregarded 
factors (Fig. 4).

\begin{tabular}{||l|r|}
\hline \multirow{2}{*}{ Statistic } & \multicolumn{1}{c}{ Summary Statist } \\
\cline { 2 - 2 } & \multicolumn{1}{c|}{ Value } \\
\hline Multiple R & 0,992460778 \\
\hline Multiple R? & 0,984978397 \\
\hline Adjusted R? & 0,963948152 \\
\hline $\mathrm{F}(7,5)$ & 46,8362785 \\
\hline $\mathrm{P}$ & 0,00029249303 \\
\hline Std.Err. of Estimate & 0,0343026129 \\
\hline
\end{tabular}

Fig. 4. Indicators of the adequacy of the model.

Analysis of the statistical significance of the model parameters allows us to conclude that they are significant. The zero hypothesis in this case is not taken into account, because what actually means that the coefficient of determination is significant.

\section{Conclusion}

Consequently, model (2) can be used for further analysis. Proceeding from this, it can be stated that with an increase in the volume of gross external debt by 1 thousand dollars of US , the level of stability of the financial system of the country decreases by an average of 1 point, with the growth of GDP per 1 thousand dollars. The US level of stability of the financial system of the country increases by an average of 0.4 and with an increase in exports by 1 thousand dollars. The US level of stability of the financial system of Ukraine increases by an average of 0.6 points.

This research can serve as the basis for the adoption by the relevant state institutions of sound decisions on ensuring the stability of the financial system of Ukraine.

Table 3. Parameters of built models for samples.

\begin{tabular}{|c|c|c|c|c|c|c|c|}
\hline $\begin{array}{ll}\text { Parameters } & \text { Sample } \\
\text { at the indicator } & \end{array}$ & 1 & 2 & 3 & 4 & 5 & 6 & 7 \\
\hline & 0.653719 & 0.682680 & 0.661740 & 0.635063 & 0.645879 & 0.657426 & 0.595660 \\
\hline GDP & 0.000004 & 0.000004 & 0.000004 & 0.000004 & 0.000004 & 0.000004 & 0.000004 \\
\hline Gross External Debt & 0.000001 & 0.000001 & 0.000001 & 0.000002 & 0.000001 & 0.000001 & -0.000001 \\
\hline Domestic dept & -0.000019 & -0.000020 & -0.000018 & -0.000020 & -0.000019 & -0.000020 & -0.000010 \\
\hline Internal debt service & 0.000065 & 0.000079 & 0.000063 & 0.000054 & 0.000066 & 0.000066 & -0.000031 \\
\hline Maintenance of external debt & -0.000237 & -0.000274 & -0.000242 & -0.000227 & -0.000257 & -0.000232 & -0.000149 \\
\hline Export of goods and services & 0.000003 & 0.000002 & 0.000003 & 0.000003 & 0.000003 & 0.000002 & 0.000006 \\
\hline Consolidated Budget Revenues & -0.000011 & -0.000011 & -0.000011 & -0.000011 & -0.000011 & -0.000011 & -0.000010 \\
\hline
\end{tabular}

\begin{tabular}{|l|c|c|c|c|c|c|c|c|}
\hline $\begin{array}{l}\text { Parameters Sample } \\
\text { at the indicator }\end{array}$ & 8 & 9 & 10 & 11 & 12 & 13 & 14 & 15 \\
\hline & & & & & & & & \\
\hline GDP & 0.648292 & 0.651688 & 0.677078 & 0.651688 & 0.674089 & 0.639576 & 0.609431 & 0.635501 \\
\hline Gross External Debt & 0.000004 & 0.000005 & 0.000005 & 0.000005 & 0.000004 & 0.000001 & 0.000002 & 0.000007 \\
\hline Domestic dept & 0.000001 & 0.000001 & 0.000001 & 0.000001 & 0.000000 & 0.000002 & 0.000003 & -0.000001 \\
\hline Internal debt service & -0.000019 & -0.000021 & -0.000019 & -0.000021 & -0.000013 & -0.000030 & -0.000035 & -0.000012 \\
\hline Maintenance of external debt & 0.000071 & 0.000095 & 0.000046 & 0.000095 & 0.000048 & 0.000138 & 0.000206 & 0.000048 \\
\hline Export of goods and services & 0.000003 & -0.000242 & -0.000210 & -0.000242 & -0.000218 & -0.000249 & -0.000446 & -0.000227 \\
\hline Consolidated Budget Revenues & -0.00001 & -0.000001 & 0.000002 & 0.000001 & 0.000001 & 0.000006 & 0.000004 & 0.000002 \\
\hline
\end{tabular}

\section{References}

1. Monitoring of the factors that create the risks of sustainability of public finances in Ukraine. http://ief.org.ua/wp-content/uploads/2015/05 (2015)

2. Danylenko, A.I., Zymovets, V.V.: Risks and Threats to the Security of the Public Finance Sector of Ukraine: An Analytical Report. NAS of Ukraine. 7-8 (2013)

3. The Methodology for Calculating the Level of Economic Security of Ukraine: Order of the Ministry of Economy of Ukraine dated 02 March 2007. tinyurl.com/yytexv91 (2007). Accessed 21 Mar 2019

4. Sovereign Bond Interest Rate Spreads, basis points over US Treasuries. https://tinyurl.com/y57s6qxy (2018). Accessed 21 Mar 2019

5. Yankovy, O.G., Goncharenko, O.M.: Analysis of Sustainable Development of Enterprises by the
Normalized Scale of Hurst. Bul. of the VPI. 2, 35-38 (2012)

6. Derbentsev, V.D., Serdyuk, O.A., Solovyov, V.M. and Sharapov, O.D.: Synergetic and econophysics methods for the study of dynamic and structural characteristics of economic systems. Brama-Ukraine, Cherkasy (2010)

7. Ministry of Economic Development and Trade of Ukraine. www.me.gov.ua (2019). Accessed 21 Mar 2019

8. External sector statistics. tinyurl.com/yy $8 w d x 2 h$ (2019). Accessed 21 Mar 2019

9. World Bank Open Data. tinyurl.com/y59qa6po (2019). Accessed 21 Mar 2019

10. Makhanets, L.L.: Estimation of the financial system stability of the country. ONU herald. 23, 5(70), 185 190 (2018)

11. Panasenko, G.: Criteria and indicators of financial sector stability assessment. Bul. of the KNUTE. 6, 99-110 (2010) 